\title{
Azar y contingencia: Universos en disputa
}

Chance and contingency: Universes in dispute

\author{
Nora Wolfzun ${ }^{1}$ \\ Universidad de Buenos Aires - Argentina
}

Revista Derechos en Acción ISSN 2525-1678/ e-ISSN 2525-1686

Año 5/N 15 , Otoño 2020 (21 marzo a 21 junio), 511-524

DOl: https://doi.org/10.24215/25251678e410

Acabo siempre aludiendo al centro sin la menor garantía de saber lo que digo, cedo a la trampa fácil de la geometría con que pretende ordenarse nuestra vida de occidentales

Julio Cortázar, Rayuela.

Lewis Carroll era escritor y matemático. La trama que el autor desarrolla en su magistral Alicia en el país de las maravillas se despliega en el marco de una jugada de naipes sin reglas, o con leyes que cambian sin causa alguna. La lectura de Alicia recrea un piso imaginario y cognitivo propicio para introducirnos en las reflexiones filosóficas de Quentin Meillassoux en su libro Después de la finitud, en el que el concepto de transfinito (infinito de infinito) lo lleva a afirmar categóricamente que las propias leyes que gobiernan nuestro mundo y sus cosas pueden ser de otra manera, sin razón alguna, abonando la idea central del libro: la contingencia radical como absoluto especulativo.

El presente trabajo diseña su campo de relevancia en torno al intercambio de categorías, insumos y recursos analíticos entre la Crítica Jurídica y el Realismo Especulativo, específicamente centrado en la lectura de Después de la finitud, de Meillassoux.

1 Docente de Filosofía del Derecho de la Universidad de Buenos Aires. 
Publicado hace ya casi una década, tuvo un impacto masivo en la historia inmediata de la filosofía y una fuerte incidencia en temas fundamentales de la escena contemporánea (como la crítica de las ideologías y el retorno de lo religioso), revitalizando al mismo tiempo, según nos cuenta Nocetti en la nota a la presente edición, el desolado paisaje filosófico a partir de las desapariciones de Deleuze y de Derrida.

Después de la finitud y los debates que generó y genera, puede ser pensado como el más reciente punto de inflexión al interior de un movimiento filosófico francés que Alain Badiou (2013, p. 9-25) ubica en la segunda mitad del siglo XX, período que el autor llama 'filosofía francesa contemporánea' y cuya batalla conceptual en torno a la idea de sujeto acusa la herencia de Descartes.. Sobre este trasfondo filosófico, en la primera década del siglo XXI irrumpe un movimiento que en principio se lo puede leer como una empresa de signo inverso, preocupada no en los problemas del sujeto, sino en la condición real del objeto (Quentin Meillassoux, Graham Harman, Ian Hamilton Grant y Ray Brassier dieron por fundado el llamado Realismo Especulativo en el año 2007). A pesar de las tendencias contradictorias al interior de esta corriente, sus integrantes confluyen, sin embargo, en sostener un elemento común: la primacía del objeto y el repudio de la "filosofía del acceso humano" (correlacionismo).

En el prefacio de Después de la finitud, Alain Badiou retoma una problemática central en la obra de Meillassoux, que partió en dos la historia del pensamiento. ¿De dónde proviene la necesidad de las leyes de la naturaleza en la medida en que la experiencia sensible no puede garantizar ninguna? Frente a este planteo, llamado 'problema de Hume' en nombre de quien lo expuso en su forma más clara, Kant concluye que esta necesidad, al no poder provenir de nuestra recepción sensible (que sería cambiante y caótica), debe provenir de otra fuente: la actividad constituyente de un sujeto universal que llama sujeto trascendental. Esta distinción entre recepción empírica y la constitución trascendental es el marco obligado de todo pensamiento moderno. Sin embargo, Meillassoux por 
un lado deshace las pretensiones necesitantes de la metafísica clásica y por el otro, la partición crítica entre empirismo y trascendencia. Demuestra que otra comprensión del problema de Hume había quedado disimulada y que nos lleva a una partición distinta: no hay ningún fundamento aceptable para la necesidad de las leyes de la naturaleza. Su 'demostración' es que hay una sola cosa absolutamente necesaria: la contingencia de las leyes de la naturaleza a partir de la teoría matemática del transfinito. Una de sus tesis centrales es la que sostiene el alcance ontológico del teorema de Cantor, que determina la pensabilidad matemática de la des-totalización numérica. Lo cuantificable no constituye un todo y esa in-totalización recibe el nombre de transfinito. Con el teorema de Cantor, lo posible es intotalizable (Meillassoux, 2015, p. 166-169).

Discutir en torno a la estabilidad o contingencia de las leyes es un problema filosófico ya repertoriado, dice Meillassoux. El problema de Hume para este autor concierne al hecho de saber qué nos garantiza que la física misma y no tal o cual teoría (Karl Popper), sea posible mañana (Meillassoux, 2015, p. 140). Para dar cuenta del problema de Hume, se han perfilado tres respuestas: metafísica, escéptica y trascendental kantiana, que Meillassoux critica para luego fundamentar la propia, de tipo especulativo ${ }^{2}$.

\footnotetext{
2 Haremos una breve referencia a las tres miradas. La respuesta metafísica consiste en demostrar la existencia de un principio absoluto que gobierna nuestro mundo. A la manera de un discípulo de Leibniz, se demostraría la existencia necesaria de un dios perfecto. La eternidad y estabilidad de nuestro mundo estará garantizada por la eternidad de la perfección divina misma. La respuesta escéptica, que responde a la perspectiva de Hume, rechaza toda solución metafísica al problema de la causalidad. 0 sea que no podemos establecer vía razonamiento la estabilidad futura de las leyes naturales. Hay dos medios de establecer la verdad de una existencia o de una inexistencia: la experiencia y el principio de no-contradicción. Ninguno de esos dos nos permite demostrar la necesidad de la conexión causal. Nuestra creencia en la necesidad de las leyes proviene del hábito o el acostumbramiento. La respuesta trascendental de Kant, más precisamente la deducción objetiva de las categorías desarrollada en la "Analítica de los conceptos" de la Crítica de la Razón Pura, consiste en una demostración a través del absurdo: supongamos que no hay ningún tipo de necesidad causal. Lo que resulta para Kant es un desorden fenoménico tal que ninguna objetividad e incluso ninguna conciencia, podrían subsistir duraderamente. La hipótesis de la contingencia de las leyes está refutada por el hecho de la representación.
} 
Las tres perspectivas sostienen un postulado común: todas consideran como un punto adquirido la verdad de la necesidad causal (Meillassoux, 2015: 145). Se trata de una evidencia que nunca se cuestiona. La respuesta especulativa reformula el problema de Hume: en lugar de preguntarnos cómo demostrar la necesidad que se supone verídica de las leyes físicas, debemos preguntarnos cómo explicar la estabilidad manifiesta de las leyes físicas si éstas se suponen contingentes. ¿Cómo puede resultar un mundo estable a partir de leyes contingentes? Formulado de esta manera, el problema puede recibir, según Meillassoux, una respuesta satisfactoria.

Conocemos la aventura que dio lugar a las geometrías noeuclideanas (por el absurdo, se llegó a una nueva geometría tan coherente como la euclideana pero diferente de ella). Lo que Meillassoux propone es intentar lo mismo, pensar a través del absurdo en suprimir el nexo causal: poco a poco vamos a descubrir que ese universo no causal es un universo tan susceptible de coherencia como el universo causal y tan capaz de dar cuenta de nuestra experiencia presente, pero liberado de los enigmas inherentes a la creencia en la necesidad física.

La respuesta especulativa afirma, como uno de sus ejes centrales, que la contingencia de las leyes naturales es inaccesible al razonamiento aleatorio (Meillassoux, 2015: 161), es decir, contingencia y azar están enmarcados por distintos universos de sentido.

El azar presupone un conjunto previo de leyes que permiten su efectuación. La noción de azar es sólo pensable bajo la condición de leyes físicas inalterables. En cambio, la contingencia puede afectar las condiciones mismas que permiten a los acontecimientos azarosos producirse. Una resolución especulativa satisfactoria del problema de Hume debería exponer en qué podría consistir una condición precisa de estabilidad del caos. Esta condición existe, es de naturaleza matemática: se trata de lo transfinito, susceptible de conducirnos a una distinción rigurosa entre contingencia y azar. La axiomática 'standard' de los conjuntos (o la teoría llamada ZF por Zermelo-Fraenkel) 
progresivamente elaborada en la primera mitad del siglo XX a partir de los trabajos de Cantor, contiene como una de sus propiedades más destacables la pluralización inclaudicable de las cantidades infinitas. El teorema de Cantor enuncia lo siguiente: dado un conjunto cualquiera, cuente sus elementos, luego compare ese número con el número de los posibles reagrupamientos de esos elementos. Se obtendrá siempre el mismo resultado: el conjunto 'B' de los reagrupamientos de un conjunto 'A' es siempre más grande que 'A', así 'A' sea infinito. Desde la revolución cantoriana del conjuntismo, nada nos permite afirmar que lo concebible es necesariamente totalizable, porque un elemento fundamental de dicha revolución consistió en la destotalización del número. Para una respuesta especulativa, semejante totalización de lo concebible no puede de ahora en más ser garantizada a priori (Meillassoux, 2015: 165). Disponemos de una axiomática susceptible de ofrecernos medios para pensar que lo posible es intotalizable, refutando la inferencia necesarista de Kant y con ella la razón de creer en la necesidad de las leyes físicas.

Meillassoux enfatiza el hecho que el pensamiento más poderoso del acontecimiento incalculable es un pensamiento todavía matemático y no artístico o poético o religioso (2015:174): refiere a una realidad que no se deja medir por ningún número, finito ni infinito, y cuya sobre-inmensidad es la que permite la estabilidad del mundo visible.

\section{Rupturas y puntos de encuentro con la Crítica Jurídica}

El fin del mundo común ha llegado cuando se ve sólo bajo un aspecto y se le permite presentarse únicamente bajo una perspectiva.

Hannah Arendt, La condición bumana

Este trabajo se propone generar un puente analítico entre la contingencia como absoluto especulativo y las reflexiones en torno al derecho desde las formulaciones de la Crítica Jurídica, 
puente que nos habilite a pensar en sintonías y rupturas entre ambas perspectivas.

El mundo en que vivimos constituye una explosión fenoménica de gran magnitud, frente a la cual lecturas reduccionistas sólo colaboran en profundizar el empobrecimiento analítico y conceptual. El derecho como fenómeno social, es mucho más que un conjunto de normas: es facticidad y validez, convención y azar, orden y transformación, verdad y ficción, tecnología y práctica social, agencia y sistema, consenso y coerción (Cárcova, 2007: 165). La práctica social del derecho condensa en tiempo y espacio un cierto sentido de lo jurídico a través de estrategias que responden tanto a movimientos de conservación y estabilidad (que le otorgan seguridad y fijeza) como movimientos de transformación que imprimen la contingencia y dinámica indispensables para un derecho flexible y epocal.

Desde el punto de vista epistemológico, las interrogaciones de Meillassoux sobre 'estabilidad', 'necesidad' (su diferencia, su no inferencia, etc.) y 'contingencia' afectan a la misma definición que damos del derecho en tanto práctica social que articula funciones de conservación y de cambio. O sea que tanto la definición como las funciones del derecho crítico se ven interrogadas por el desarrollo de Meillassoux, desde el centro conceptual de sus postulados básicos (la capacidad del derecho de articular orden y azar) hasta otros temas derivados e igualmente medulares, como el diseño de los derechos humanos y la crítica de las ideologías.

Comencemos por una mirada rupturista entre ambas perspectivas: si hay un tema que unifica a las distintas corrientes al interior del Realismo Especulativo es su rechazo del llamado 'correlacionismo'. Las perspectivas jurídicas críticas, por el contrario, muestran un fuerte apego y adhesión al eje correlacionista. Veamos.

Uno de los problemas fundamentales de la filosofía hasta la emergencia del pensamiento kantiano era pensar la sustancia; a partir de Kant, la correlación, es decir, el pensamiento no podía salir de él mismo para comparar el mundo en sí y el mundo 
para nosotros: en el momento que pensamos que tal propiedad pertenece al mundo en sí, esa propiedad se revela ligada a nuestro pensamiento. Ya no es el sustrato (la Idea, el átomo, Dios) sino el correlato (sujeto-objeto, noético-noemático, lenguajereferencia) el nuevo eje estructurador del pensamiento moderno.

Meillassoux describe dos correlacionismos, débil y fuerte. El modelo 'débil' de Kant mantiene la pensabilidad de la cosa en sí, pero no admite su conocimiento (la aplicación de las categorías a lo suprasensible). La cosa en sí es no contradictoria y efectivamente existe. Podemos pensarla pero no podemos conocerla, está por fuera de nuestras representaciones.

Para el modelo 'fuerte' de correlacionismo, es ilegítimo tanto pensar como conocer el en-sí. Este modelo responde al círculo correlacional. Nadie volvió de una exploración de un en-sí para garantizarnos semejante absoluticidad del sentido. Todo es correlato ser-pensamiento.

Este modelo fuerte y la irremediable facticidad de las formas (no podemos más que describir las formas espacio-tiempo) está representado por la filosofía analítica de Wittgenstein del Tractatus, por la cual sostiene que la forma lógica del mundo no puede ser dicha a la manera de un hecho en el mundo sino 'mostrada'; escapa de las categorías de la ciencia o de la lógica. Escapa del discurso de la lógica el hecho mismo de que el mundo sea decible. "Hay, ciertamente, lo inexpresable. Se muestra, es lo Místico“. Es la expresión de una imposibilidad (Meillassoux, 2015: 73). Por su parte, Heidegger (¿Qué es metafísica?) afirma "el ente es". Que haya ente (hombre) escapa a la soberanía de la lógica y de la razón metafísica, y esto en virtud de una 'facticidad' de ese 'hay'. Esto marca nuestra incapacidad de dar fundamento absoluto de lo que es. En síntesis, son dos operaciones inherentes al renunciamiento del absoluto y al primado del correlato.

Los dos medios principales de la correlación en el siglo XX, la conciencia y el lenguaje, son, en términos de Francis Wolff (Dire le monde), objetos-mundo: para ellos, todo está 
adentro, porque para poder pensar en algo hay que poder tener conciencia de ello. Y entonces nos quedamos encerrados o en la conciencia o en el lenguaje, que lo dice. En este sentido, no tienen exterior. Pero en otro sentido, están completamente vueltos hacia el exterior, porque tener conciencia es tener conciencia de algo. Y hablar es necesariamente hablar de algo. Es como una jaula transparente, dice Wolff. Todo está afuera, pero es imposible salir. Se trata de un 'afuera claustral' (Meillassoux, 2015: 31). No disponemos de ningún punto de vista desde el cual podamos observar esos objetos-mundo desde el exterior. Son dos caras de un frente a frente. Es en este sentido que los modernos, dice Meillassoux, hemos perdido 'el gran afuera', que era indiferente a que lo pensemos o no.

El derecho crítico responde al piso epistemológico de lo que Meillassoux llama 'correlacionismo fuerte'. La co-implicancia sujeto-objeto es estructura fundamental del mismo. En Heidegger, la co-pertenencia originaria entre hombre y ser, llamada Ereignis, es fiel a la exigencia correlacional, porque ser y hombre no pueden ser planteados como dos 'en-sí' que sólo entrarían en relación en una segunda instancia. Por el contrario, están constituidos originariamente por su pertenencia mutua originaria (Meillassoux, 2015: 33).

El derecho crítico refiere a una situación determinada, a un cierto marco contextual, a un cierto juego de lenguaje, a una comunidad interpretativa, desechando enunciados jurídicos para todos los hombres, en todas las épocas y lugares. El derecho como un juego de lenguaje (en el sentido que Wittgenstein le da al sintagma) legitima sus enunciados de manera inmanente y contextual; gesta un cierto sentido de lo legal y lo prohibido, lo justo y lo injusto, con insumos diversos que emergen de los niveles normativos, sus interpretaciones y del imaginario social, articulando convención e invención de manera constante y dinámica. Nunca se habla tabula rasa: nuestros discursos, escritos, textos, jamás son dados o simples hechos de la naturaleza. Los efectos de sentido jurídico son productos históricos y culturales, procesos vivientes, atravesados por tensiones múltiples, 
ambivalencias, contrasentidos. El derecho en tanto experiencia modula su singular relación con la referencia, con lo real, con lo posible, con lo virtual, con lo irreal (Antoine Berman, 2014: 17).

Para un derecho crítico, entonces, el derecho es correlato y correlato fuerte. No existe el 'gran afuera', sino que responde a la imagen de Francis Wolff de una jaula transparente cerrada en el círculo correlacional ser-sujeto, y al mismo tiempo abierta hacia afuera. Hay una renuncia a pensar un absoluto, admitiendo la facticidad de lo dado como hecho y como invariante estructural, lo cual marca nuestra incapacidad, desde el pensamiento, de saber acerca de ella.

\section{Puntos de encuentro}

Sin embargo, la Crítica Jurídica adhiere a pensar la categoría de la 'necesidad' en términos afines a los desarrollos de Meillassoux. Veamos entonces algunos sub-temas del derecho crítico frente a las postulaciones realistas.

\section{Las funciones del derecho}

El derecho como fenómeno social sedimenta sentidos epocales en torno a lo justo y lo injusto, lo legal y lo prohibido, pero al mismo tiempo habilita estructuralmente sus posibilidades de transformación. La estabilidad del derecho garantiza el orden y puesta en regla de las conductas humanas, al mismo tiempo que habilita su modificación. El derecho crítico se mueve, entonces, entre estrategias de estabilidad (=conservación) y contingencia (=transformación, lo no repertoriado) pero no apela a la necesidad, es decir, invoca en su trama la estabilidad pero no la necesidad. Precisamente la categoría de la 'necesidad' es la que Meillassoux combate frontalmente, es decir, hay un punto de encuentro entre el autor y la Crítica Jurídica en torno a este eje analítico.

La estabilidad es sedimentación, anclaje más o menos duradero en el tiempo, encauzamiento de expectativas de comportamiento, pero no necesidad o fijeza ontológica alguna, lo cual 
implica sustraer la carga necesarista de importantes temas jurídicos. Cómo se piensa la 'estabilidad' en el derecho, o dicho de otra manera, cómo se 'conserva' sentido jurídico: en la práctica cotidiana de los usuarios del derecho, ellos recrean y dan vida a las figuras jurídicas; los operadores o expertos jurídicos lo conservan en su tarea hermenéutica, ratificando un cierto sentido de lo justo o lo injusto; las normas son depositarias de la sedimentación de sentido de un grupo social determinado. La estabilidad en derecho genera la previsibilidad necesaria para actuar sobre un piso jurídico consensuado y contextual. Por otro lado, y al mismo tiempo, la trama jurídica habilita su propia transformación, es decir, reconoce en los operadores jurídicos una actividad hermenéutica al interior de la cual pueden producir pequeños o grandes deslizamientos de sentido, desde retoques hasta importantes innovaciones. Pero no sólo los expertos ejercen una función transformadora al operar con el material jurídico, sino la sociedad civil en tanto destinataria del derecho puede generar cambios a través de reclamos y reivindicaciones de distinto tenor. En sintonía con el razonamiento de Meillassoux, la estabilidad no implica necesidad y la contingencia de las prácticas jurídicas no deriva en un hiper-caos, sino que la constancia de las mismas está asegurada por la infinita posibilidad de los mundos. El llamado a la filosofía del derecho es concebir los mundos en plural.

\section{Derechos humanos}

Pensar lo transfinito implica no sólo un replanteo de las funciones paradojales del derecho, sino que es un desafío para quienes afirman la existencia de derechos humanos 'totalizables', eternos, necesarios, universales. Para la Crítica Jurídica, los derechos humanos son contingentes y no necesarios, históricos, contextuales, en línea con la idea de in-totalización cantoriana, que nos permite abordar especulativamente el tema de los derechos humanos, sin ninguna necesidad de acudir a la metafísica.

"Los llamados derechos humanos o fundamentales no demandan ninguna metafísica, ni siquiera de una metafísica constructiva. 
Sólo pueden ser pensados como construcciones humanas, históricas y contextuales. Adquisiciones civilizatorias que se transforman con el desarrollo de la evolución social, su progresiva ampliación, expansión y consolidación" (Cárcova, 2008: 133)³.

La historia nos muestra que la lucha por el reconocimiento de la calidad de persona, la libertad, la igualdad, la autonomía, es producto de largas marchas y contramarchas, avances y retrocesos. Lo que llamamos derechos humanos son una creación occidental, ciertas garantías consagradas como fundamentales para la convivencia social y que adquirieron carácter positivo como plexo de derechos y vinculados a ciertas formas de la moral social vigente, pero no adquieren carácter de derechos por su contenido moral, sino por su sanción positiva, tal como se encuentra prevista en el orden jurídico. La definición de derechos humanos responde a valores y concepciones que son propias de una cultura y no de todas las culturas (Cárcova, 2008: 136-137)

Las necesidades humanas son infinitas y el orden de prioridades no es cuestión de metafísica, sino de decisión política, producto de un proceso de lucha social por la apropiación del sentido. La relativa indeterminación de los derechos humanos permite que se resignifiquen epocalmente, al ritmo de las transformaciones en el campo de las valoraciones y de los conocimientos especializados.

La fundamentación (consensual y contextual) de los derechos humanos sólo es posible sin metafísica, en línea con el desarrollo de Meillassoux y la idea de in-totalización numérica.

\section{Crítica de las ideologías}

El abandono de la metafísica dogmática es la condición mínima de toda crítica de las ideologías, que consiste en demostrar la contingencia de una situación social presentada como inevitable y necesaria (implica desmontar lo necesario en

3 Cárcova (2008: 133-140) plantea discrepancias con Robert Alexy, quien ancla la existencia de DDHH en su 'fundamentabilidad', dimensión que presupone elementos metafísicos. 
relación con lo contingente). La resignificación que hace Meillassoux de las nociones de necesidad y de contingencia está en sintonía directa con la crítica de las ideologías que tematiza la Crítica Jurídica. El derecho es un discurso ideológico que gestiona sus niveles de visibilidad e invisibilidad (alude-elude), movilizando estrategias de necesidad y de contingencia. Lo que es 'necesario' (un paradigma necesario, una teoría jurídica necesaria, la invocación de algún principio necesario) es sólo funcional a un esquema de poder y deviene 'contingente' (y viceversa) según las luchas de sentido, es decir, como productos precarios y temporales de las confrontaciones semánticas para el logro de algún sentido hegemónico. El abandono de la carga necesarista que Meillassoux nos propone permite gestionar los niveles de alusión y elusión, cuya dinámica es el motor de toda crítica ideológica.

\section{La in-totalización como apuesta del derecho}

Azar y contingencia pertenecen a universos de sentido diferentes. Cada vez que hablamos de azar o de álea, se perfila el tema del Dado-Todo (la clausura inalterable del número de posibles). También, observa Meillassoux, el azar conecta con la aparente gratuidad del juego, con cierta liviandad de la vida, pero también con el frío (y clausurado) cálculo de las frecuencias (el mundo de los seguros de vida, de los riesgos ponderables, por ejemplo).

El término contingencia, en cambio remite al latín contingere, lo que sucede lo suficiente para que nos suceda, algo que por fin sucede, algo diferente, que escapando a todos los posibles ya repertoriados, pone fin a la vanidad de un juego donde todo, incluido lo improbable, es previsible.

Pensar la contingencia como absoluto especulativo (poder ser/poder no ser sin razón ni causa alguna) nos permite reflexionar en torno al derecho en sus posibilidades de transformación dinámica y contextual. Lejos de abandonar las milenarias y refinadas técnicas jurídicas que apuntalan virtuosamente la 
previsibilidad y la seguridad en el campo del derecho, habrá sin embargo que estar siempre alerta frente a la clausura y el excesivo dogmatismo que hacen irrespirable la vida del derecho, lo asfixian, le impiden dar lo que tiene de innovador y sensible de cara a los cambios y a la diferencia. La idea de Meillassoux acerca de la necesidad de la contingencia nos acerca a un derecho más humano.

\section{Bibliografía}

Alexy, Robert (2008)." ¿Derechos humanos sin metafísica?", en Ideas y Derecho. Anuario de la Asociación Argentina de Filosofía del Derecho, Buenos Aires, La Ley-Número 6.

Badiou, Alain ( 2013). La aventura de la filosofía francesa, Eterna Cadencia, Buenos Aires.

Berman, Antoine (2014). La traducción y la letra o el albergue de lo lejano, Dedalus Editores, Buenos Aires.

Cárcova, Carlos ( 2007). Las Teorías Jurídicas Post Positivistas, LexisNexis, Buenos Aires.

Cárcova, Carlos (2008). “ Nota sobre el artículo “¿Derechos humanos sin metafísica? De Robert Alexy". Derechos humanos: naturaleza y cultura"?", en Ideas y Derecho. Anuario de la Asociación Argentina de Filosofía del Derecho, Buenos Aires, La Ley-Número 6.

Harman, Graham (2015). Hacia el realismo especulativo, Caja Negra, Buenos Aires.

Latour, Bruno (2012). Nunca fuimos modernos. Siglo Veintiuno Editores, Buenos Aires.

Meillassoux, Quentin (2015). Después de la finitud. Ensayo sobre la necesidad de la contingencia. Caja Negra, Buenos Aires.

Meillassoux (2007). Contingencia y absolutización de lo uno. Conferencia en La Sorbona, en el Coloquio "Metafísica, ontología y henología", organizado por Paris-I el 16 de marzo.

Ricoeur, Paul (2009). Tiempo y Narración III, Siglo Veintiuno, España.

Vattimo, Gianni (2014). De la realidad a la verdad. Editorial FEDUN, Buenos Aires. 
Wolfzun, Nora (2014). "El derecho: una verdad traducida", en Los derechos fundamentales en la Constitución: interpretación y lenguaje, Jurisprudencia Argentina, AbeledoPerrot, Buenos Aires.

Zizek, Slavoj (2008). Ideología. Un mapa de la cuestión (comp.), Fondo de Cultura Económica, Buenos Aires. 